\title{
The role of concordant and discordant comorbidities on performance of self-care behaviors in adults with type 2 diabetes: a systematic review
}

This article was published in the following Dove Press journal:

Diabetes, Metabolic Syndrome and Obesity: Targets and Therapy

\author{
Fekadu Aga' \\ Sandra B Dunbar ${ }^{2}$ \\ Tedla Kebede ${ }^{3}$ \\ Rebecca A Gary ${ }^{2}$ \\ 'Department of Nursing, School of \\ Nursing \& Midwifery, College of Health \\ Sciences, Addis Ababa University, Addis \\ Ababa, Ethiopia; ${ }^{2} \mathrm{Nell}$ Hodgson \\ Woodruff School of Nursing, Emory \\ University, Atlanta, GA 30322, USA; \\ ${ }^{3}$ Tikur Anbessa Specialized Hospital, \\ Diabetes \& Endcrinology Unit, \\ Department of Internal Medicine School \\ of Medicine, College of Health Sciences, \\ Addis Ababa University, Addis Ababa, \\ Ethiopia
}

Background: Most patients with Type 2 diabetes (T2D) have high number of comorbid chronic conditions that can affect their self-care abilities. Guidelines for diabetes self-care behaviors are disease specific with little attention given to managing T2D with other comorbidities. Identifying comorbidities that either improve or potentially diminish the individual's capacity to perform effective self-care behaviors is essential to enhance clinical outcomes. One such framework conceptualizes comorbidities as concordant or discordant with diabetes pathophysiological pathways and care goals.

Objective: The purpose of this systematic review was to examine the role of diabetes-concordant and discordant chronic conditions on the performance of self-care behaviors in adults with T2D.

Methods: A comprehensive literature search was undertaken to identify published English language articles through the following five electronic databases: PubMed, CINAHL, PsycINFO, ISI Web of Science, and EMBASE. Quantitative studies published from March 2006 to April 2018 were included. Quality of evidence was evaluated using the Joanna Briggs Institutes Critical Appraisal Tools (JBI-CAT) and rated using Quality Assessment Tool for Quantitative Studies (QATQS).

Results: The initial database search identified 1,136 articles but only 33 studies that met the inclusion criteria were included. The most common concordant comorbidity was hypertension while depression was the most common discordant condition. Adherence to medications was the most frequent diabetes self-care behavior reported and tended to be higher among concordant comorbidities. The findings showed mixed results concerning the effect of some concordant comorbidities such as hypertension, hyperlipidemia, retinopathy, and heart failure on diabetes self-care behaviors. But, there is agreement across studies that diabetesdiscordant comorbidities have a more detrimental effect on self-care behaviors.

Conclusions: Concordant comorbidities may improve diabetes self-care, but the evidence is inconclusive. Future research using well designed studies are needed to examine the complex relationship between diabetes self-care and comorbidities.

Keywords: comorbidity, concordant comorbidity, diabetes self-care behaviors, discordant comorbidity, multimorbidity, type 2 diabetes

\section{Introduction}

Diabetes mellitus (DM) is one of the largest global health challenges of the $21 \mathrm{st}$ century as the number of cases continues to rise. ${ }^{1}$ The epidemic is mainly from type
Correspondence: Fekadu Aga Department of Nursing, School of Nursing \& Midwifery, College of Health Sciences, Addis Ababa University, P.O. Box 9083, Addis Ababa Tel +125 I9| 1033684

Email fiqaaduuagaa@yahoo.com 
2 diabetes mellitus (T2D) that is driven by genetic, epigenetic, environmental, and behavioral factors such as sedentary lifestyle, consumption of energy dense diet and obesity. ${ }^{1-3}$ According to the International Diabetes Federation (IDF), about 425 million people between 20 and 79 years of age lived with DM in 2017 worldwide. $^{4}$ The global age-standardized diabetes prevalence is $9.0 \%$ in men and $7.9 \%$ in women though there is great regional variation. ${ }^{5}$ More than $90 \%$ of all DM cases are T2D which is continuously increasing. ${ }^{4,6}$

Patients with T2D have a higher number of comorbid conditions, also referred to as multimorbidity, which may result in treatment conflict, ${ }^{7}$ reduced glycemic control, ${ }^{8,9}$ increased cost of treatment, ${ }^{10,11}$ and lower quality of life. ${ }^{12}$ Multiple studies in T2D have demonstrated multimorbidity prevalence rate as high as $97.5 \% .^{7,8,10,13-16}$ Studies show that low socioeconomic status, obesity and job strain, ${ }^{17}$ age, race/ethnicity, ${ }^{18}$ and low health literacy ${ }^{19}$ are associated with increased prevalence of comorbidity in T2D. Furthermore, about $50 \%$ of T2D patients face premature mortality from cardiovascular comorbidities such as coronary artery disease, heart failure and stroke, and approximately $10 \%$ from renal failure. ${ }^{20}$

The successful management of T2D requires a patient's engagement in self-care on a daily basis to control its progression and to prevent serious complications, reduce rates of hospitalization and cost of care, and improve quality of life. ${ }^{21-24}$ Diabetes self-care involves sustained engagement in multidimensional behavioral actions including healthy dietary intake, physical activity, blood glucose monitoring, medication adherence, problem solving, and risk reduction such as foot checks and smoking cessation. ${ }^{25,26}$ Antecedent factors such as demographic, psychosocial, clinical, and environmental variables can influence the patient's successful performance of diabetes self-care. ${ }^{26-28}$ The influence of these factors may become even more important when there is another serious comorbid condition or if multimorbidity exists.

There is a need for further research to understand the impact of comorbidities on optimal diabetes self-care in order to maximize self-care for patients with $\mathrm{T} 2 \mathrm{D}$ and multimorbidity. ${ }^{29}$ Guidelines currently are primarily disease-specific and provide little direction for self-care for T2D in the presence of other chronic conditions. ${ }^{30}$ Interventions that target self-care for T2D in the presence of multimorbidity are also limited. Understanding the relationship between diabetes self-care and other chronic conditions may lead to more effective interventions for this complex population. ${ }^{31-33}$
A framework developed by Piette and Kerr ${ }^{34}$ that conceptualizes chronic conditions as concordant or discordant with diabetes care has gained momentum over the last decade to help guide management of T2D and coexisting multimorbidity. Diabetes-concordant comorbidities (such as cardiovascular, metabolic and renal disease) share parts of the same overall pathophysiologic profile and care management as T2D. For example, blood pressure and lipid monitoring are overlapping cardiovascular risk reduction goals for diabetes and cardiovascular disease and likely to lead to better outcomes for both conditions. Magnan and colleagues ${ }^{35}$ found that having more concordant conditions was linked to better quality of care for diabetes.

Diabetes-discordant comorbidities have no direct relationship with diabetes in their pathophysiologic profile or care management and include chronic conditions such as asthma, cancer and mental illness such as depressive symptoms. ${ }^{35-40}$ Treatment for some of these discordant conditions might interfere with treatment for T2D. For example, using steroids for asthma treatment would increase blood glucose and conflict with the treatment for diabetes while depressive symptoms have been shown to lead to poorer adherence to self-care in chronic conditions, including T2D.Time limitations, conflicting care goals, and other challenges may result in a lower quality of care for diabetes and the discordant condition as compared to having concordance or a single condition. Using a Delphi study method, Magnan and colleagues $^{38}$ identified 12 concordant and 50 discordant comorbidities in DM. The findings from this study suggested that concordant chronic conditions are more easily managed because care goals are similar and more likely to be identified and addressed by care providers. However, Magnan and colleagues ${ }^{35}$ noted that the presence of more dominant concordant conditions such as advanced heart failure may reduce diabetes selfcare behaviors; others have not shown this effect. Discordant conditions are less likely to be identified and included in care goals which may contribute to poorer diabetes control, additional complications, and higher health care utilization.

The role that the concordance-discordance framework may have in identifying key determinants or challenges in diabetes self-care has received little attention in the literature. Awareness of obstacles faced by patients with T2D who are managing multiple chronic conditions will help inform future strategies for more effective diabetes 
self-care. The purpose of this systematic review was to examine the role of diabetes-concordant and discordant chronic conditions on the performance of self-care behaviors in adults with T2D.

\section{Methods}

The process of conducting and reporting this systematic review was guided by the Preferred Reporting Items for Systematic Reviews and Meta-Analysis (PRISMA) statements. $^{41,42}$ The PICO (Participant-Intervention /Exposure-Comparison-Outcome) format was used to guide the research question and to establish inclusion and exclusion criteria for articles in this review.

\section{Search strategy}

The construction of the search strategy in this review was based on the guideline developed by the Joanna Briggs Institute (JBI). ${ }^{43}$ A total of 68 search terms were used. Examples include: "Type 2 diabetes," "adult," "comorbidity," "concordant comorbidity," "discordant comorbidity," "multimorbidity," "myocardial infarction," "cerebrovascular disease," "heart failure," "chronic renal failure," "asthma," "depression," "self-care behavior," "self-care," "diet," "physical activity," "foot care," and "medication adherence."Medical subject heading $(\mathrm{MeSH})$ and free text words were used for searching the databases. Truncation and Boolean operators AND/OR - were used to combine the different search terms. Finally, the search was refined by publication date (March 2006 to April 2018), English language, and study design (cross-sectional survey, case-control, cohort, nonrandomized clinical trial, and randomized clinical trial).

Studies were identified by searching the following electronic databases: PubMed, CINAHL, PsycINFO, ISI Web of Science, and EMBASE. Further search of Google Scholar, Cochrane Library, and websites of pertinent organizations such as World Health Organization (WHO), International Diabetes Federation (IDF), and American Diabetes Association did not yield one additional study. However, scanning of the reference lists of the retrieved articles provided two additional studies. The literature search was grouped into the following comorbidity categories: concordant comorbid conditions only; discordant comorbid conditions only; and both concordant and discordant comorbid conditions.

\section{Inclusion and exclusion criteria}

Only quantitative studies that examined the relationship between concordant and discordant comorbid conditions and diabetes self-care behaviors in adults ( $\geq 18$ years) with
T2D were included in this review. Studies that addressed either overall diabetes self-care behavior or specific selfcare behaviors such as diet, medication, blood glucose self-monitoring, exercise, foot care, and smoking as an outcome variable were included. Studies not available in English, conference abstracts and books were not included in the review. The time frame for selection of articles was informed by the publication of a conceptual framework for understanding diabetes care in the context of concordant and discordant comorbidities. ${ }^{34}$

\section{Study selection}

All articles retrieved from the search process were saved into the Endnote citation manager. Duplicates were removed, and the remaining records were screened for study inclusion. Eligibility was assessed independently in an unblinded standardized manner by 2 reviewers. Disagreements between reviewers were resolved by consensus. A two-stage screening process was undertaken using a checklist we developed for this purpose. First, the titles and abstracts of the articles were screened for relevance in relation to the PICO question. In the second round, full-text screening was performed. After screening, the studies were assessed for methodological quality in a two-step process. In the first step, the Joanna Briggs Institute (JBI) Critical Appraisal Tools ${ }^{44}$ was used to determine to what extent a study had addressed possible biases and included the PICO of interest in this review. In the second step, the remaining studies were rated as strong, moderate, or weak using the Quality Assessment Tool for Quantitative Studies ${ }^{45}$ in six domains: selection bias, design, confounders, blinding, data collection methods and withdrawals and dropouts. The overall rating for the study was decided by assessing the six domain ratings. Those with no weak ratings and at least four strong ratings were considered strong evidence. Studies with less than four strong ratings and one weak rating were considered moderate while those with two or more weak ratings were considered weak evidence.

\section{Data collection}

Data were extracted using a standardized grid format that followed recommendations from the Cochrane Review ${ }^{46}$ and the Joanna Briggs Institute. ${ }^{47}$ Information related to data source, setting, study aim, design, sample characteristics, comorbidities types, outcome measurement, and results were extracted from individual studies. 


\section{Data analysis and synthesis}

A narrative synthesis method was used in this systematic review because the heterogeneity observed in the study designs and methods of the selected studies did not allow the application of pooled analytical meta-analysis procedures. A narrative synthesis organizes and summarizes studies using words to explain the findings. ${ }^{48}$ In this review, the use of a narrative approach facilitated description of concordant, discordant or the presence of both conditions in T2DM which helped to compare the impact of each on diabetes self-care.

\section{Result}

The initial database search identified 1,136 articles. However, only 33 studies met the inclusion criteria and were included in this review. The number of studies excluded at each stage of duplication removal, screening, and eligibility assessment process is shown in Figure 1.

\section{Study characteristics}

Table 1 provides a summary of the 33 studies meeting eligibility criteria and included in the systematic review.
Most studies included T2D self-care with discordant comorbidities $(\mathrm{n}=23)$ compared to self-care with concordant chronic conditions $(n=6)$. Four studies included T2D self-care with both concordant and discordant chronic conditions. Twenty one studies were cross-sectional, ${ }^{49-69}$ eight were cohort studies, ${ }^{70-77}$ two were case-control studies, ${ }^{78,79}$ one was non-randomized intervention, ${ }^{80}$ and one was randomized controlled trial. ${ }^{81}$ Seventeen studies were conducted in the United States (US), four in Canada, two studies each in Malaysia, China and Ireland, and one study each in the Netherlands, Australia, Belgium, Romania, and Jordan. The sample size of the studies ranged from 64 to 740,197 with a median of 615 . The studies reported the mean age of the participants ranging from 47.7 to 70.8 years. One study was rated as weak, 27 as moderate, and five as strong.

Twenty studies measured generic or overall diabetes self-care behavior as an outcome. Specific diabetes selfcare behaviors were also measured as an outcome and included: medication adherence $(\mathrm{N}=9)$, exercise behavior $(\mathrm{N}=4)$, dietary behavior $(\mathrm{N}=2)$, foot care $(\mathrm{N}=1)$, blood glucose monitoring $(\mathrm{N}=1)$, and smoking behavior $(\mathrm{N}=1)$.

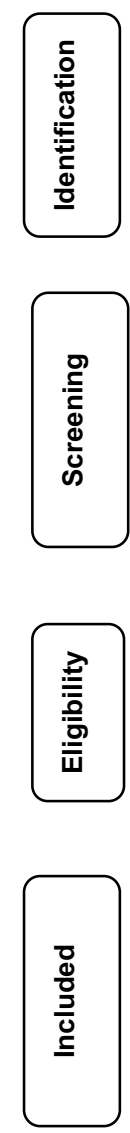

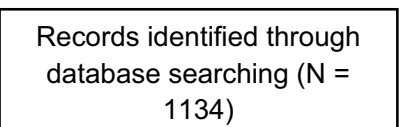

1134)

\section{Additional records identified through other sources $(N=2)$}



Figure I PRISMA flow chart. 


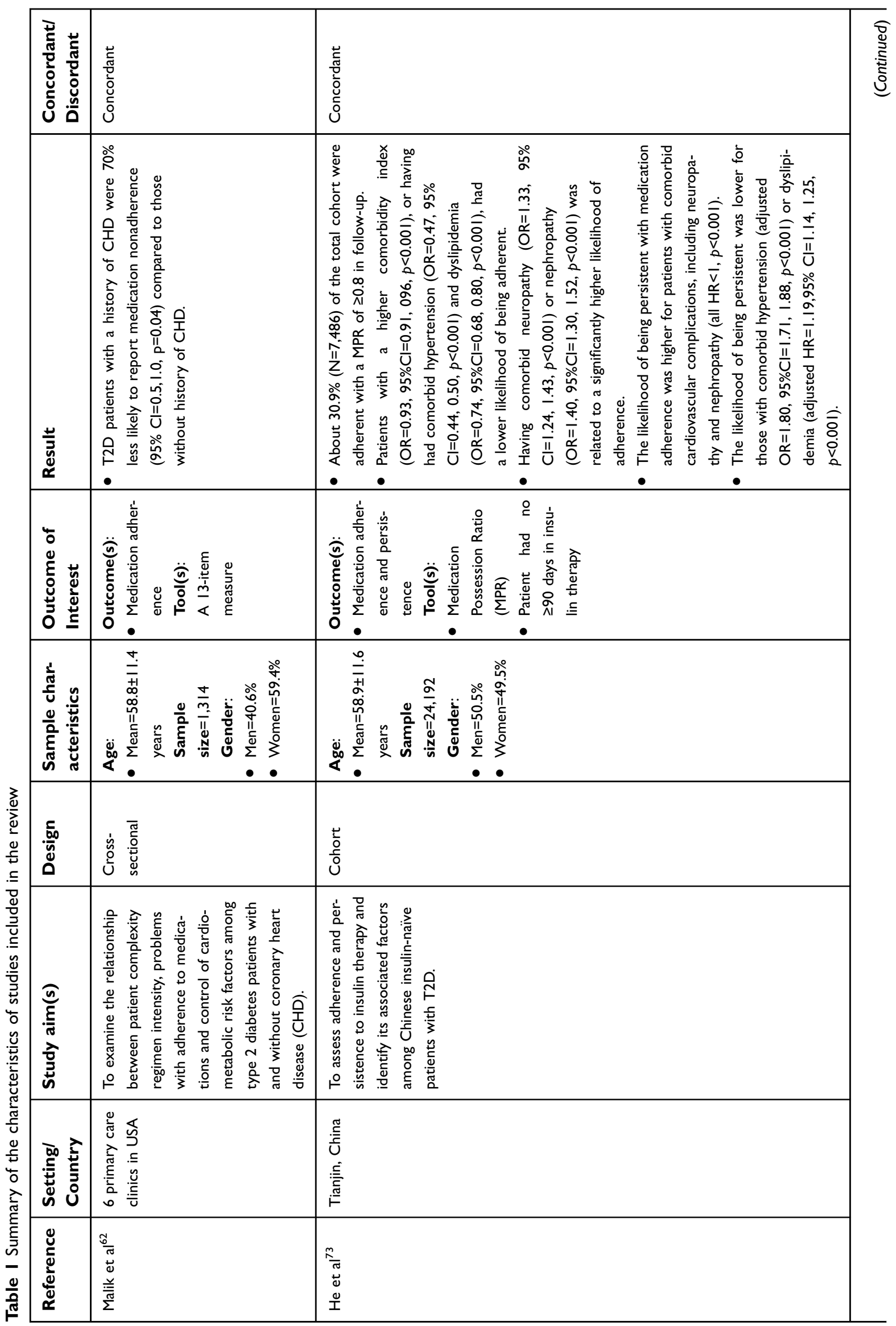




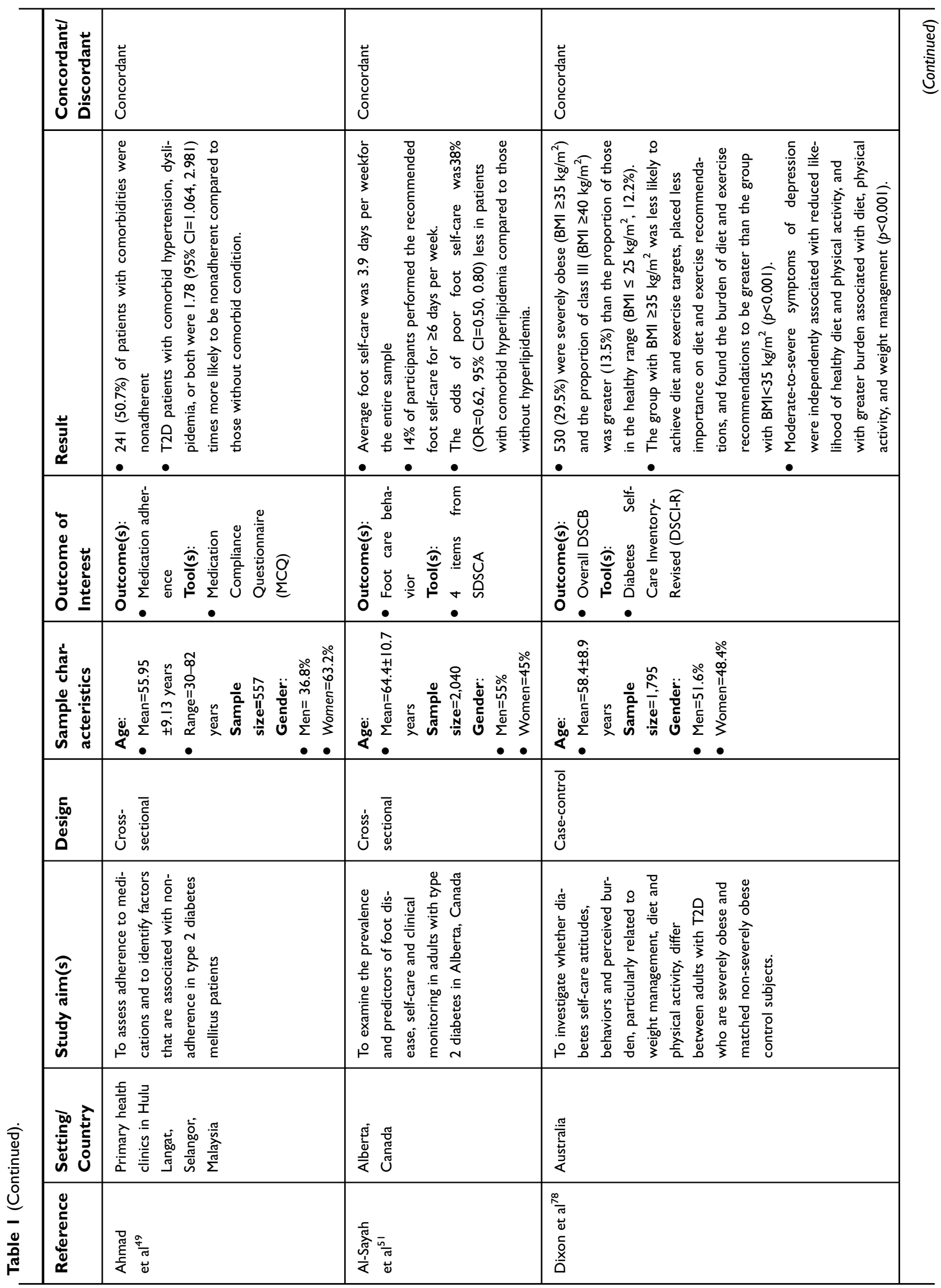




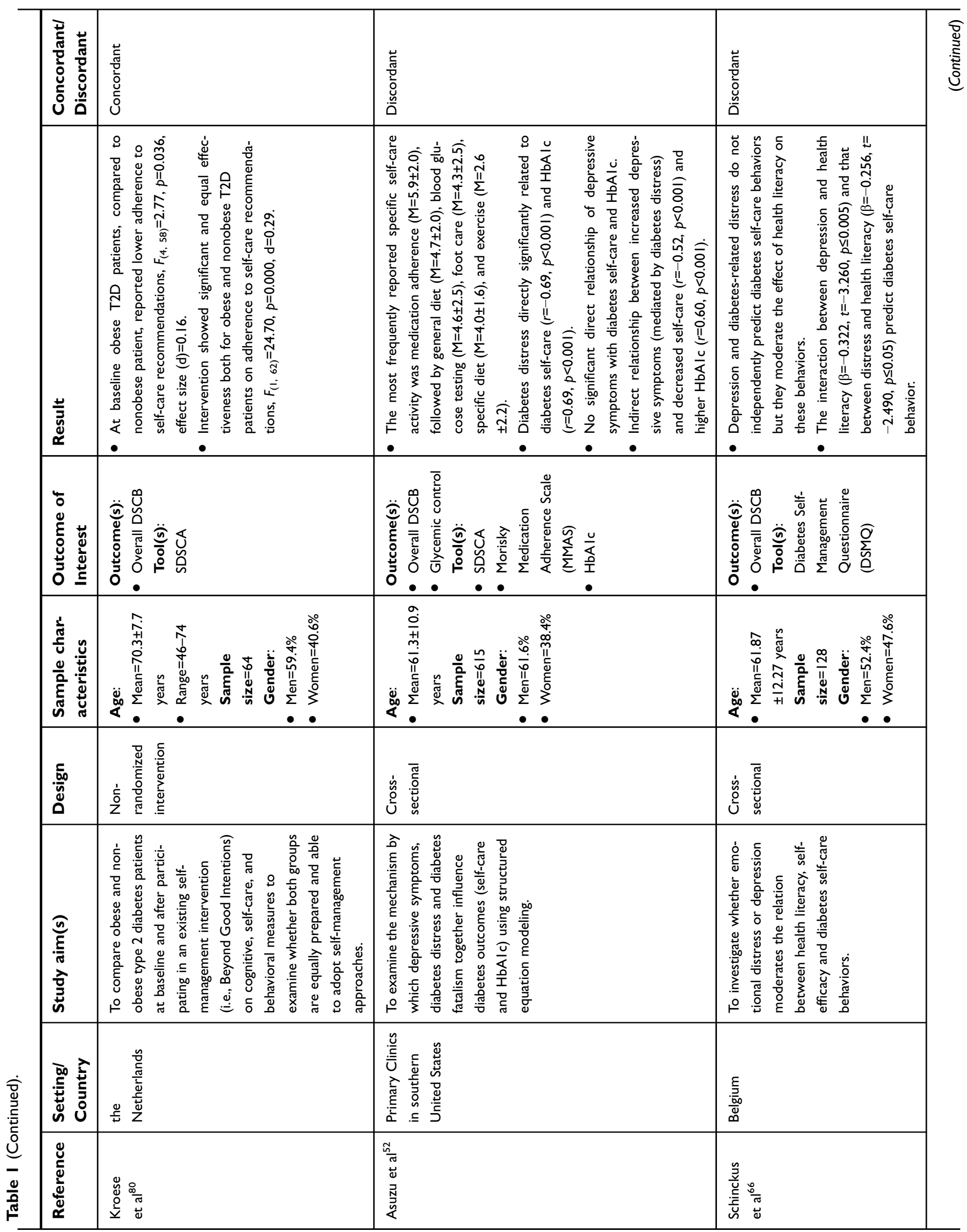









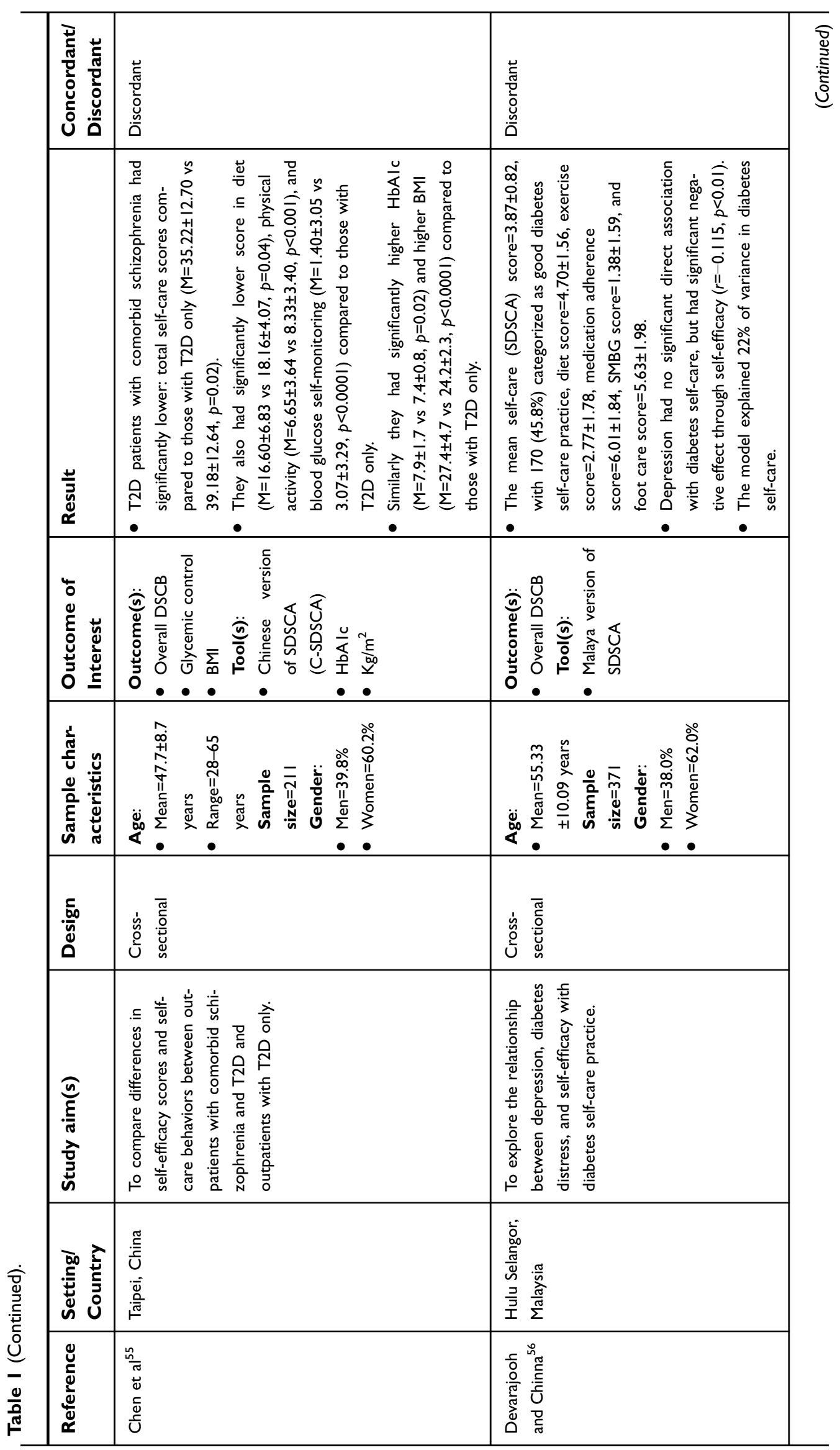




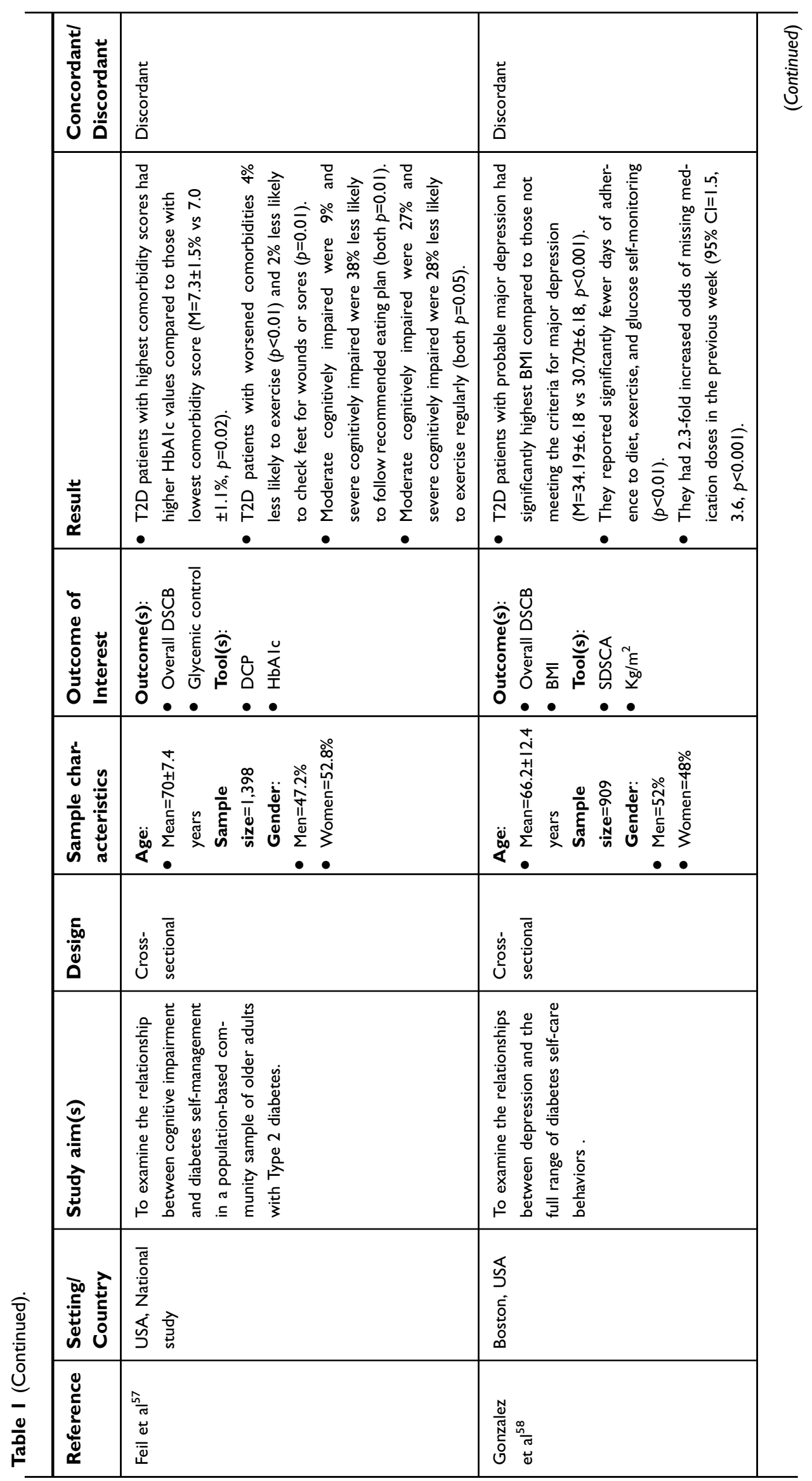




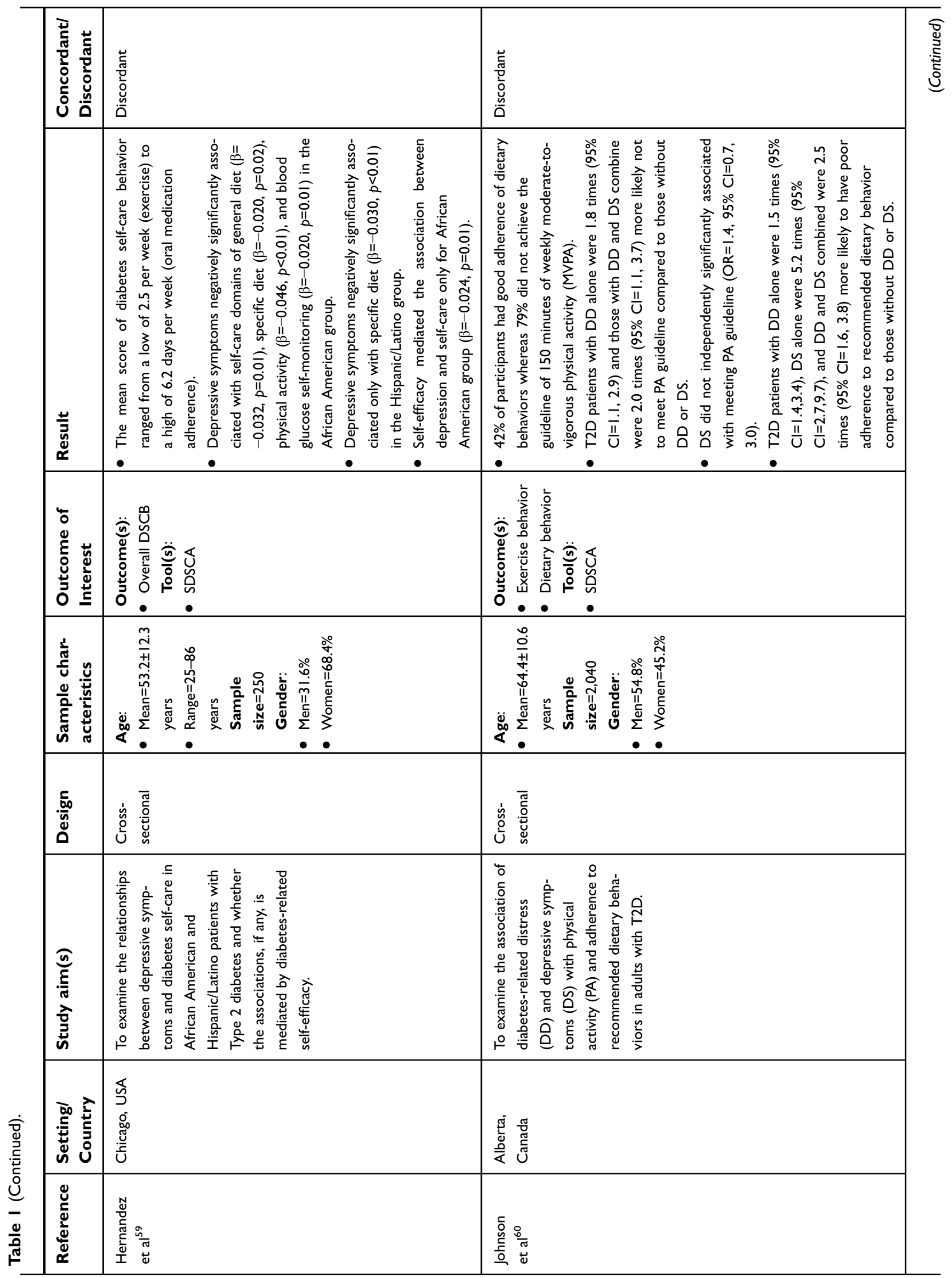




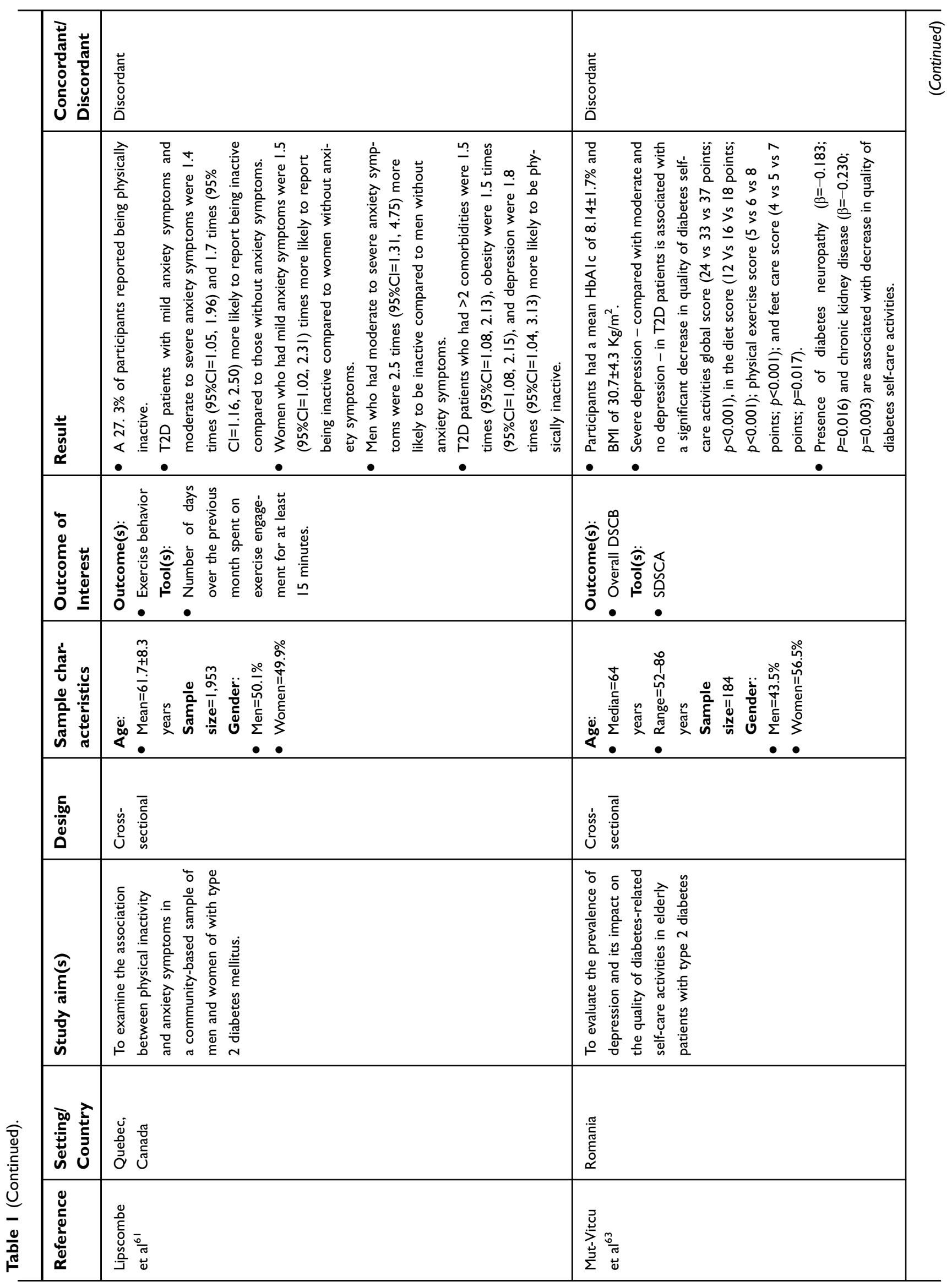




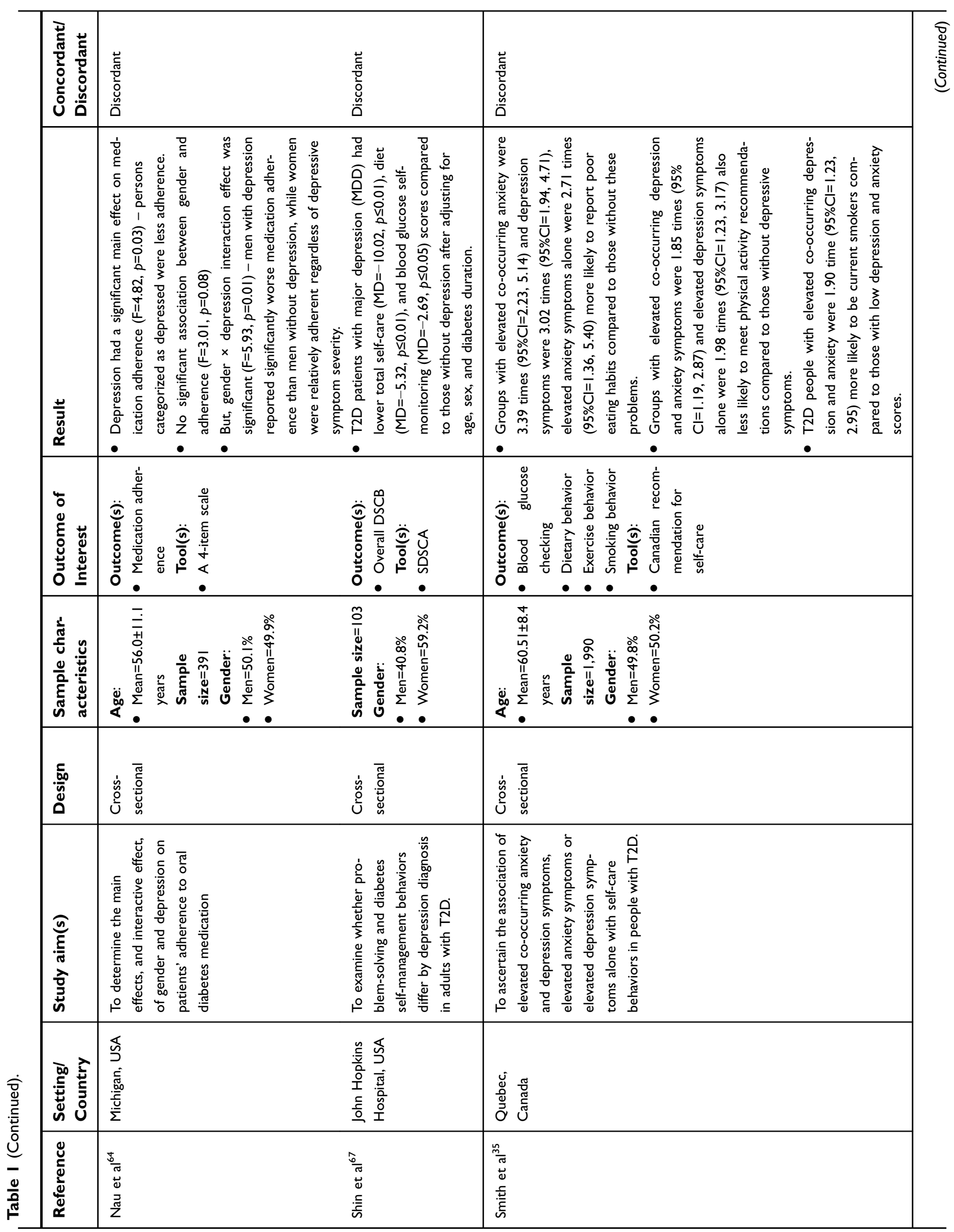




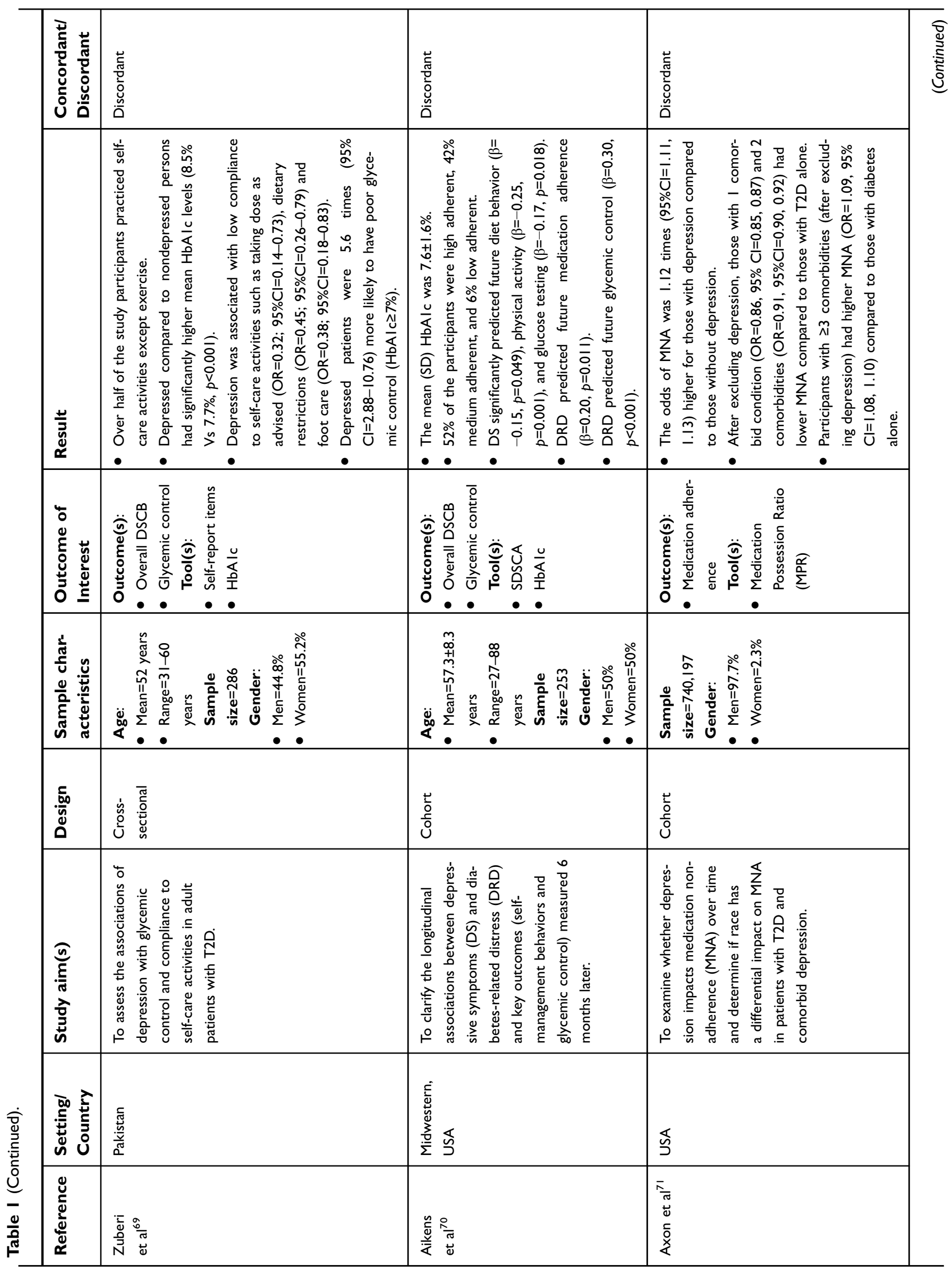














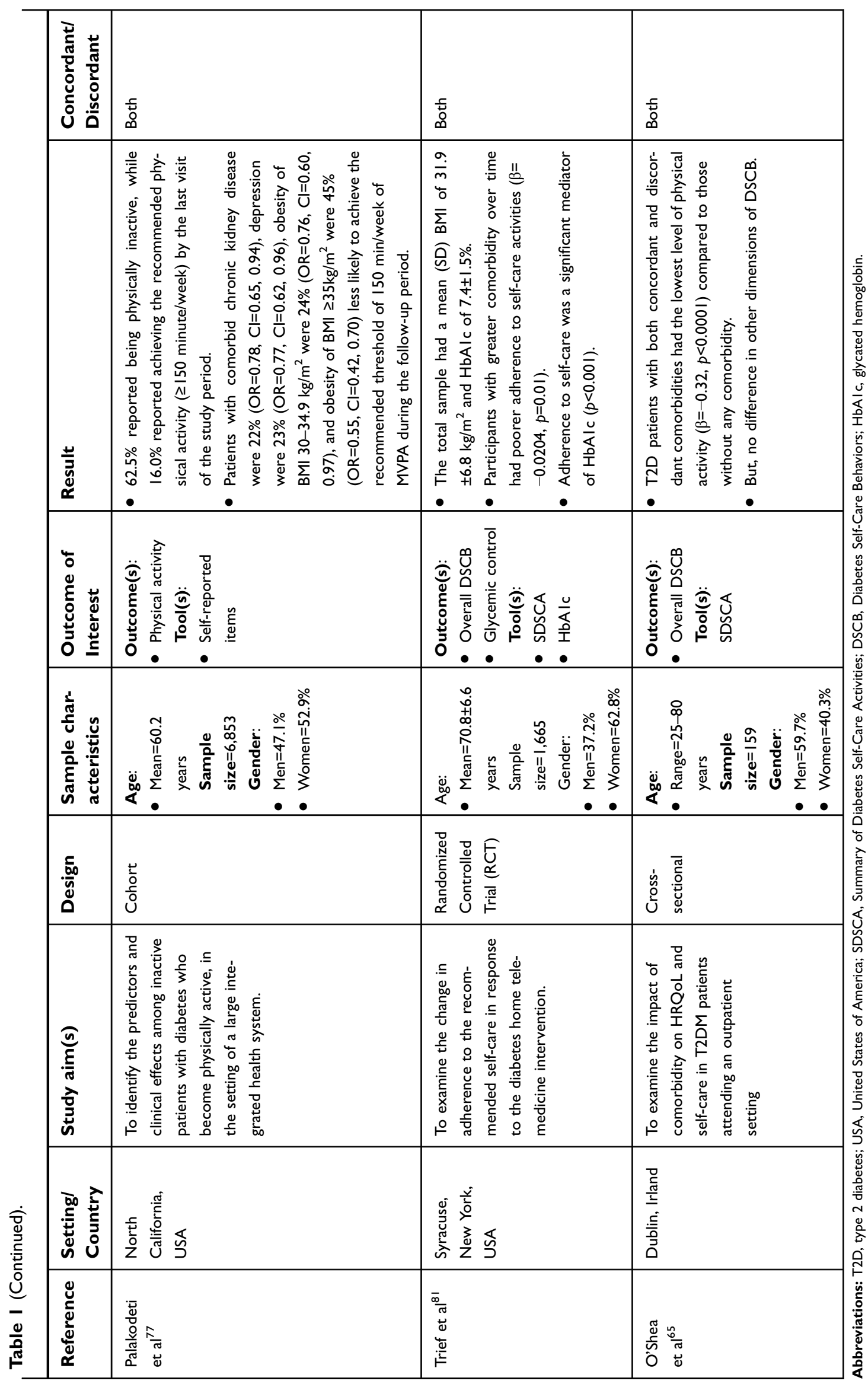




\section{Concordant and discordant comorbidities}

The most frequently measured T2D concordant and discordant comorbidities in relation to self-care behaviors are shown in Table 2. Hypertension, obesity and chronic kidney disease were the most frequent concordant conditions with heart failure being the least frequently measured. Depression was the most frequently measured discordant comorbidity.

\section{Frequency of diabetes self-care behaviors in concordant and discordant comorbidities concordant}

Medication adherence was the most frequently reported self-care behavior for concordant conditions. Two of the

Table 2 Comorbid conditions investigated by the studies included in this review

\begin{tabular}{|l|l|}
\hline Comorbid condition & Number of studies \\
\hline Diabetes-concordant comorbidities: & \\
Hypertension & II \\
Chronic kidney disease & 9 \\
Obesity & 8 \\
Coronary artery disease & 8 \\
Retinopathy & 7 \\
Hyperlipidemia & 6 \\
Neuropathy & 4 \\
Peripheral vascular disease & 4 \\
Heart failure & 3 \\
\hline Diabetes-discordant comorbidities: & \\
Depression & 26 \\
Osteoarthritis & 5 \\
Lung disease & 4 \\
Cancer & 3 \\
Liver disease & 3 \\
Schizophrenia & 2 \\
Cognitive impairment & 2 \\
Anxiety & 2 \\
Asthma & 2 \\
Stomach/intestinal ulcer & 2 \\
Back pain & 2 \\
Anemia & 2 \\
Thyroid disease & 1 \\
Substance use disorder & 1 \\
Sleep disturbance & 1 \\
Migraines & 1 \\
Addison's disease & \\
Cushing's syndrome & \\
Fluid/electrolyte disorder & \\
\hline
\end{tabular}

four studies that focused on medication adherence in concordant comorbid conditions described that more than $50 \%$ of their participants were adherent. ${ }^{62,73}$ The other two studies, however, reported that compared to those without comorbid conditions, T2D patients with concordant comorbidities including hypertension, dyslipidemia and obesity were $1.78(95 \% \mathrm{CI}=1.064,2.981)$ times less likely to be adherent to the medication regimen ${ }^{49}$ and less likely to be physically active $(\beta=-0.32, p<0.0001) .{ }^{65}$ Another study evaluating foot self-care in adults with T2D reported that those with hyperlipidemia were $38 \%$ less likely to perform the recommended foot self-care for $\geq 6$ days per week. ${ }^{51}$ A randomized controlled trial tested the effects of a telemedicine intervention (Informatics for Diabetes Education and Telemedicine Project) on adherence over time in older Hispanic and African Americans reported that greater comorbidity over time had worse adherence to diabetes self-care activities $(\beta=-0.0204$, $p=0.01$ ) compared to those without comorbidities. ${ }^{81}$

\section{Discordant}

The most common self-care behavior reported for discordant conditions was also medication adherence followed by dietary and physical activity. Only three studies reported the mean score of the overall diabetes self-care activities. ${ }^{50,56,79}$ AmongT2D patients with discordant comorbid depression, the overall mean diabetes self-care score ranged from 3.87 to 40.5. This shows the mean of total diabetes self-care score on the Summary of Diabetes Self-Care Activities (SDSCA) for diet, exercise, medication, blood glucose monitoring, foot care, and smoking cessation which indicates less diabetes self-care performance. Two additional studies also reported that only $50 \%$ of their study participants practiced diabetes self-care behaviors in the presence of depressive symptoms. ${ }^{69,70}$

Regarding specific diabetes self-care behaviors, four studies examined depressive symptoms and found that taking prescribed medications was the most frequently performed while exercise was the least often performed..$^{50,52,59,79}$ In contrast, another study investigating depressive symptoms reported that taking medications as prescribed was the most frequently performed self-care behavior $(\mathrm{M}=6.01 \pm 1.84)$ during the week, followed by exercise $(\mathrm{M}=2.77 \pm 1.78)$ and blood glucose self-monitoring $(\mathrm{M}=1.38 \pm 1.59) .{ }^{56}$ Johnson and colleagues ${ }^{60}$ examined dietary and physical activity behaviors among adults with diabetes-related distress and depressive symptoms. In this study, only $42 \%$ had good adherence to the recommended diabetes dietary recommendations and 
almost $80 \%$ did not meet physical activity guidelines Participants with depressive symptoms were 5.2 less likely to adhere to dietary guidelines compared to those without depressive symptoms, but this was not independently associated with physical activity level. ${ }^{60}$ Persons with mild anxiety symptoms and moderate to severe anxiety symptoms were 1.4 times and 1.7 times more likely to report being physically inactive than persons without anxiety symptoms, respectively. Feil and colleagues ${ }^{57}$ reported that older T2D patients with greater cognitive impairment were less likely to adhere to exercise $(p<0.05)$, diet $(p<0.01)$ or check feet for wounds $(p=0.01)$ compared to those without cognitive impairment. In addition, as cognitive impairment worsened, adherence to each diabetes self-care behavior declined. Axon and colleagues ${ }^{71}$ examined whether depression affects medication adherence over time. Findings revealed the odds of being medication nonadherent was 1.12 times higher among those with comorbid depression compared to those with T2D alone. The same study revealed that having three or more comorbid conditions, after excluding depression, was associated with higher medication nonadherence (OR 1.09, [95\% CI: $1.08,1.10])$ while having two or less comorbidities was associated with lower medication nonadherence compared to those with $\mathrm{T} 2 \mathrm{D}$ alone.

\section{Both concordant and discordant}

Two studies that measured exercise and medication adherence behaviors in those with both concordant and discordant comorbid conditions such as depression, cognitive impairment, chronic kidney disease, and obesity found that over $62.5 \%$ of their participants did not achieve the recommended weekly moderate-to-vigorous physical activity level $^{77}$ and $30 \%$ were medication nonadherent. ${ }^{76}$ In the anxiety study described above, if there were greater than 2 comorbidities including obesity, the likelihood of being physically inactive was almost two-fold ${ }^{61}$ compared to those without comorbidities.

\section{Summary of concordant and discordant comorbidity and diabetes self-care behaviors}

Two cohort studies ${ }^{73,76}$ and two cross-sectional studies ${ }^{51,62}$ reported that there were significantly higher odds of medication adherence and foot self-care in T2D patients with specific concordant comorbidities such as hyperlipidemia and coronary heart disease compared to those without these comorbidities. In contrast, two cohort, ${ }^{73,77}$ two cross-sectional, $^{53,63}$ one case-control, ${ }^{78}$ and one interventional $^{80}$ study reported that $\mathrm{T} 2 \mathrm{D}$ patients with concordant comorbid hypertension, dyslipidemia, obesity, and chronic kidney disease had significantly lower odds of achieving the recommended diabetes self-care behaviors than those without these comorbid conditions.

Studies have shown the negative association between diabetes-discordant comorbidities and diabetes self-care behaviors. A cohort study ${ }^{76}$ found statistically significant lower odds of medication adherence in T2D patients with discordant comorbidities overtime. Similarly, 14 of the 21 cross-sectional studies reviewed reported that $\mathrm{T} 2 \mathrm{D}$ patients with discordant comorbid depression, ${ }^{54,58,59,63,64,67}$ diabetes-related distress, ${ }^{52,60}$ anxiety, ${ }^{35,61}$ schizophrenia, ${ }^{55}$ impaired sleep quality and daytime sleepiness, ${ }^{53}$ and cognitive impairment ${ }^{57}$ had statistically significant lower odds of performing the recommended diabetes self-care behaviors compared to those without these comorbidities. The two case-control studies also reported that T2D patients with comorbid depression had significantly lower scores for diabetes self-care behaviors compared to those without depression. ${ }^{78,79}$ In addition, five of the eight cohort studies reported that T2D patients with discordant comorbid schizophrenia and alcohol or substance use disorder, ${ }^{75}$ diabetes-related distress, ${ }^{70}$ and depression ${ }^{70-72,74,75}$ had statistically significant lower odds of achieving the recommended self-care behaviors.

In several studies, depression was mediated by selfefficacy or other factors. Among seven studies depression had no direct association with diabetes self-care behavior but was mediated by self-efficacy, ${ }^{50,56,79}$ diabetes-related distress, ${ }^{52,60}$ gender, ${ }^{64}$ and health literacy. ${ }^{66}$

\section{Discussion}

Findings from this systematic review indicate that concordant and discordant comorbidities may result in poorer diabetes self-care. To our knowledge, this is the first systematic review detailing differences between concordant and discordant comorbid conditions on diabetes self-care behaviors. The findings are consistent with previous research that multimorbidity has a negative effect on the T2D patients' achievement of the recommended diabetes self-care behaviors. In general, there is support in the literature that concordant conditions may result in higher frequency and adherence of self-care behaviors than discordant. For example, O'Shea and colleagues ${ }^{76}$ directly compared concordant and discordant comorbidities on oral-hypoglycemic medication adherence and determined those with concordant conditions were 
more adherent. Other studies, however, do not support these findings. He and colleagues, ${ }^{73}$ for example, showed a positive association between peripheral neuropathy and adherence to insulin therapy, while another study showed poorer quality of diabetes self-care activities with concomitant peripheral neuropathy. ${ }^{63}$ The effect of diabetesconcordant comorbidities on diabetes self-care behaviors may vary depending on the type of comorbidity and the selfcare behavior being measured. For example, in the two studies reporting medication adherence with existing peripheral neuropathy, ${ }^{63,73}$ there were considerable differences in participant comorbidity type and the self-care behaviors measured. In the He and colleagues ${ }^{73}$ study, only concordant comorbidities and one specific behavior, medication adherence, was included. The Mut-Vitcu and colleagues ${ }^{63}$ included both concordant and discordant chronic conditions and overall diabetes self-care behaviors were measured which may explain in part, the disparate findings.

Too much of an emphasis on the features of single comorbid illnesses may result in failure to see larger patterns in the ways that treatments for T2D and comorbidities interact. ${ }^{38}$ An increased number of comorbidities was associated with a decline in diabetes self-care behaviors and is consistent with previous research. ${ }^{61,71}$ Importantly, not all comorbid conditions are the same nor have the same consequences on diabetes self-care performance. Periodic evaluation of comorbidities, particularly as they worsen, may change patient self-care priorities from diabetes to a more dominant comorbid condition resulting in poor disease control and higher risk for complications. ${ }^{36}$ The use of the concordance and discordance framework is beneficial toward this end and may help to identify which chronic conditions are most likely to result in poorer outcomes based on care goals of one of more dominant comorbidities. ${ }^{38}$

Results from this systematic review support previous research concerning the negative impact of diabetesdiscordant comorbidities on diabetes self-care behaviors. Most of the diabetes-discordant comorbidities involved mental health and neuropsychiatric disorders such as depression, anxiety, diabetes-related distress, cognitive decline and schizophrenia. Analyses identified that these comorbidities had a more negative impact on diabetes self-care behaviors compared to patients with T2D alone. Most of the discordant conditions were examined independently with diabetes selfcare behaviors rather than with other multiple conditions which may have influenced findings. Screening T2D patients for neuropsychological multimorbidity such as depression and cognitive decline is important because they have been shown to reduce the capability of the individual to perform effective diabetes self-care. Simple screening tests such as the Patient Health Questionnaire-9 (PHQ-9) ${ }^{82}$ and the Montreal Cognitive Assessment (MoCA) ${ }^{83}$ can be administered in clinic settings and have been previously validated in the diabetes population.

The frequency of diabetes self-care performance was lower in T2D patients with comorbid conditions compared to those without comorbidities. This is true both for the overall or global diabetes self-care behaviors and specific components including diet, exercise, blood glucose selfmonitoring, medication adherence, foot care, and smoking behaviors. There is agreement among studies ${ }^{52,56,59,79}$ that medication adherence is the most frequently performed specific diabetes self-care behaviors whereas exercise is the least performed. Thus, barriers to engagement in exercise self-care among T2D patients with comorbid conditions need to be explored in future research.

Medication adherence was the most frequently performed diabetes self-care behavior in both concordant and discordant chronic conditions, but little is known about how adults with T2D rank the importance of their specific self-care behaviors, management, and outcomes relative to those of other comorbid conditions such as hypertension or depression. A better understanding of the individual's self-care priorities and the process used for decision-making when managing other complex chronic conditions may provide additional insight on adherence to self-care. Future research is warranted to examine which strategies best organize care for T2D patients with comorbid conditions to optimize clinical outcomes and quality of life, as well as identifying self-care priorities from the patient's perspective. The number of adults experiencing T2D with multimorbidity is anticipated to increase making integration of care an essential component of diabetes management. Guidelines and interventions that encompass concordant conditions if they are found to be associated with improved diabetes self-care would be beneficial and help to personalize care goals. Worsened outcomes associated with discordant chronic conditions could be used to highlight areas where patients may need additional care to prevent or delay complications. ${ }^{35,36}$

\section{Strengths and limitations}

Comparing the effect of concordant and discordant comorbid conditions on diabetes self-care behaviors was strength because no studies have previously described diabetes selfcare using this approach. Using the diabetes-concordant and 
discordant framework can provide clinicians additional insight into which comorbid conditions may lead to better or poorer adherence to diabetes self-care behaviors. The majority of studies were cross-sectional and nonrandomized which limited the quality of evidence and interpretation of findings. Whether all confounders known to influence T2D self-care behaviors were controlled in these studies is unknown. In addition, self-reported measures were used for most studies which are less accurate and reliable. The heterogeneity of the samples, designs and measures of self-care across studies made it impossible to perform pooled analytical procedures or meta-analysis. The majority $(\mathrm{N}=26)$ of studies included in this review were conducted in highincome countries which limits the generalizability of the findings to middle and low-income countries where the rates of comorbid conditions may be higher in T2D. ${ }^{84,85}$ For instance, there was no study reported from Africa concerning the effect of comorbidities on diabetes self-care behaviors.

\section{Conclusion}

Diabetes-concordant comorbidities are associated with higher adherence to diabetes self-care behaviors than discordant, but future research is needed using more rigorous designs to better understand these complex relationships with diabetes self-care behaviors. Given the increase in multimorbidity observed among patients with T2D, guidelines are urgently needed that integrate diabetes self-care with other chronic conditions, especially discordant conditions in order to optimize clinical outcomes and quality of life.

\section{Disclosure}

The authors report no conflicts of interest in this work.

\section{References}

1. Zimmet PZ. Diabetes and its drivers: the largest epidemic in human history? Clin Diabetes Endocrinol. 2017;3(1). doi:10.1186/s4084240016-40039-40843

2. Jaacks LM, Siegel KR, Gujral UP, Narayan KMV. Type 2 diabetes: a 21st century epidemic. Best Pract Res Clin Endocrinol Metab. 2016;30:331-343. doi:10.1016/j.beem.2016.05.003

3. Unnikrishnan R, Pradeepa R, Joshi SR, Mohan V. Type 2 diabetes: demystifying the global epidemic. Diabetes. 2017;66:1432-1442. doi: $10.2337 /$ db16-0766

4. IDF. IDF Diabetes Atlas. International Diabetes Federation: 2017.

5. NCDRiskFactorCollaboration. Worldwide trends in diabetes since 1980: a pooled analysis of 751 population-based studies with $4 \cdot 4$ million participants. Lancet. 2016;387:1513-1530. doi:10.1016/ S0140-6736(16)00618-8

6. WHO. Globl Reports on Diabetes. Geneva: WHO; 2016.
7. Caughey GE, Roughead EE, Vitry AI, McDermott RA, Shakib S, Gilbert AL. Comorbidity in the elderly with diabetes: identification of areas of potential treatment conflicts. Diabetes Res Clin Pract. 2010;87:385-393. doi:10.1016/j.diabres.2009.10.019

8. Lang VB, Markovic BB. Prevalence of comorbidity in primary care patients with type 2 diabetes and its association with elevated HbA1c: a cross-sectional study in Croatia. Scand J Prim Health Care. 2016;34(1):66-72. doi:10.3109/02813432.2015. 1132886

9. Luijks H, Biermans M, Bor H, et al. The effect of comorbidity on glycemic control and systolic blood pressure in type 2 diabetes: a cohort study with 5 year follow-up in primary care. PLoS One. 2015;10(10):e0138662. doi:10.1371/journal.pone.0138662

10. O'Shea M, Teeling M, NBennet $\mathrm{K}$. The prevalence and ingredient cost of chronic comorbidity in the Irish elderly population with medication treated type 2 diabetes: a retrospective cross-sectional study using a national pharmacy claims database. BMC Health Servises Res. 2013;13(23). Available from: http://www.biomedcen tral.com/1472-6963/1413/1423

11. Li R, Bilik D, Brown MB, et al. Medical costs associated with type 2 diabetes complications and comorbidities. Am J Manag Care. 2013;19(5):421-430.

12. Adriaanse MC, Drewes HW, van der Heide I, Struijs JN, Baan CA. The impact of comorbid chronic conditions on quality of life in type 2 diabetes patients. Qual Life Res. 2016;25(1):175-182. doi:10.1007/ s11136-015-1061-0

13. Iglay K, Hannachi H, Howie PJ, et al. Prevalence and co-prevalence of comorbidities among patients with type 2 diabetes mellitus. Curr Med Res Opin. 2016;32(7):1243-1252. doi:10.1185/03007995.2016.1168291

14. Alonso-Moran E, Orueta JF, Esteban JIF, et al. Multimorbidity in people with type 2 diabetes in the Basque Country (Spain): prevalence, comorbidity clusters and comparison with other chronic patients. Eur J Intern Med. 2015;26:197-202. doi:10.1016/j.ejim.2015.02.005

15. Chen H, Zhang Y, Wu D, et al. Comorbidity in adult patients hospitalized with type 2 diabetes in Northeast China: an analysis of hospital discharge data from 2002 to 2013. Biomed Res Int. 2016;2016:1671965. doi:10.1155/2016/1671965

16. Luijks H, Schrmer T, Bor H, et al. Prevalence and incidence density rates of chronic comorbidity in type 2 diabetes patients: an exploratory cohort study. BMC Med. 2012;10(128). Available from: http:// www.biomedcentral.com/1741-7015/1710/1128

17. Ervasti J, Kivimaki M, Dray-Spira R, et al. Comorbidity and work disability among employees with diabetes: associations with risk factors in a pooled analysis of three cohort studies. Scand J Public Health. 2016;44(1):84-90. doi:10.1177/1403494815605245

18. Lopez JMS, Bailey RA, Rupnow MFT. Demographic disparities among medicare beneficiaries with type 2 diabetes mellitus in 2011: diabetes prevalence, comorbidities, and hypoglycemia events. Popul Health Manag. 2015;18(4):283-289. doi:10.1089/pop.2014.0115

19. Naskar S, Victor R, Nath K. Depression in diabetes mellitus - a comprehensive systematic review of literature from an Indian perspective. Asian J Psychiatr. 2017;27:85-100. doi:10.1016/j.ajp.2017.02.018

20. Dieren S, Bealens JWJ, Schouw Y, Grobbee DE, Neal B. The global burden of diabetes and its complications: an emerging pandemic. Eur J Cardiovasc Prev Rehabil. 2010;17(Suppl 1):S3-S8. doi:10.1097/01. hjr.0000368191.86614.5a

21. Adepoju OE, Bolin JN, Phillips CD, et al. Effects of diabetes self-management programs on time-to-hospitalization among patients with type 2 diabetes: a survival analysis model. Patient Educ Couns. 2014;95:111-117. doi:10.1016/j.pec.2014.01.001

22. Osborn CY, Bains SS, Egede LE. Health literacy, diabetes self-care, and glycemic control in adults with type 2 diabetes. Diabetes Technol Ther. 2010;12(11):913-919. doi:10.1089/dia.2010.0058

23. Song M. Diabetes mellitus and the importance of self-care. J Cardiovasc Nurs. 2010;25(2):93-98. doi:10.1097/ JCN.0b013e3181c5a364 
24. Tshiananga JKT, Kocher S, Weber C, Emy-Albrecht K, Berndt K, Neeser K. The effect of nurse-led diabetes self-management education on glycosylated hemoglobin and cardiovascular risk factors: a meta-analysis. Diabetes Educ. 2012;38(1):108-123. doi:10.1177/ 0145721711423978

25. Haas L, Maryniuk M, Beck J, et al. National standards for diabetes self-management education and support. Diabetes Educ. 2012;38 (5):619-629. doi:10.1177/0145721712455997

26. Shrivastava SR, Shrivastava PS, Ramasamy J. Role of self-care in management of diabetes mellitus. J Diabetes Metab Disord. 2013;12 (14). Available from: http://www.jdmdonline.com/content/12/11/14

27. Ahola AJ, Groop P-H. Barriers to self-management of diabetes. Diabeteic Med. 2013;30:413-420. doi:10.1111/dme.12105

28. Onwudiwe NC, Mullins CD, Winston RA, et al. Barriers to self-management of diabetes: a qualitative study among low-income minority diabetics. Ethn Dis. 2011;21:27-32.

29. Zulman DM, Asch SM, Martins SB, Kerr EA, Hoffman BB, Goldstein MK. Quality of care for patients with multiple chronic conditions: the role of comorbidity interrelatedness. J Gen Intern Med. 2014;29(3):529-537. doi:10.1007/s11606-013-2616-9

30. Roland M, Paddison C. Better management of patients with multimorbidity. Br Med J. 2013;346:f2510. doi:10.1136/bmj.f1164

31. Dunbar SB, Butts B, Reilly CM, et al. A pilot test of an integrated self-care intervention for persons with heart failure and concomitant diabetes. Nurs Outlook. 2014;62:97-111. doi:10.1016/j. outlook.2013.09.003

32. Dunbar SB, Reilly CM, Gary RA, et al. Randomized clinical trial of an integrated self-care intervention for persons with heart failure and diabetes: quality of life and physical functioning outcomes. $J$ Card Fail. 2015;21(9):719-729. doi:10.1016/j.cardfail.2015.05.012

33. Smith SM, Soubhi H, Fortin M, Hudon C, O'Dowd T. Managing patients with multimorbidity: systematic review of interventions in primary care and community settings. Br Med J. 2012;345:e5205. doi:10.1136/bmj.e5205

34. Piette JD, Kerr EA. The impact of comorbid chronic conditions on diabetes care. Diabetes Care. 2006;29(3):725-731.

35. Magnan EM, Palta M, Johnson HM, Bartels CM, Schumacher JR, Smith MA. The impact of a patient's concordant and discordant chronic conditions on diabetes care quality measures. J Diabetes Complications. 2015;29(2):288-294. doi:10.1016/j.jdiacomp.2014.10.003

36. Aung E, Donald M, Coll J, Dower J, Williams GM, Doi SA. The impact of concordant and discordant comorbidities on patient-assessed quality of diabetes care. Health Expect. 2015;18 (5):1621-1632. doi:10.1111/hex.12151

37. Lin P-J, Kent DM, Winn AN, Cohen JT, Neuman PJ. Multiple chronic conditions in type 2 diabetes mellitus: prevalence and consequences. Am J Manag Care. 2015;21(1):e23-e34.

38. Magnan EM, Gittelson R, Bartels CM, et al. Establishing chronic condition concordance and discordance with diabetes: a Delphi study. BMC Fam Pract. 2015;16:42. doi:10.1186/s12875-12015-1025312876

39. Ricci-Cabello I, Stevens S, Kontopantelis E, et al. Impact of the prevalence of concordant and discordant conditions on the quality of diabetes care in family practices in England. Ann Fam Med. 2015;13:514-522. doi:10.1370/afm.1848

40. Teljeur C, Smith SM, Paul G, Kelly A, O'Dowd T. Multimorbidity in a cohort of patients with type 2 diabetes. Eur J Gen Pract. 2013;19 (1):17-22. doi:10.3109/13814788.2012.714768

41. Moher D, Liberati A, Tetzlaff J, Altman DG; The_PRISMA_Group. Preferred reporting items for systematic reviews and meta-analyses: the PRISMA statement. PLoS Med. 2009;6(7):e1000097. doi:10.1371/journal.pmed.1000097

42. Liberati A, Altman DG, Tetzlaff J, et al. The PRISMA statement for reporting systematic reviews and meta-analyses of studies that evaluate health care interventions: explanation and elaboration. $J$ Clin Epidemiol. 2009;62:e1-e34. doi:10.1016/j.jclinepi.2009.06.006
43. Aromataris E, Ritano D. Constructing a search strategy and searching for evidence: a guide to the literature search for a systematic review. $\mathrm{Am}$ J Nurs. 2014;114(5):49-56. doi:10.1097/01.NAJ.0000446779.99522.f6

44. Joanna Briggs JBI. Intitute Reviewer's Manual 2014 Edition. Australia: JIB; 2014.

45. Thomas BH, Ciliska D, Dobbins M, Micucci S. A process for systematically reviewing the literature: providing the research evidence for public health nursing interventions. Worldviews Evid Based Nurs. 2004;1(3):176-184. doi:10.1111/j.1524-475X.2004.04006.x

46. Higgins J, Decks J. Selecting studies and collecting data. In: Higgins J, Green S, editors. Cochrane Handbook for Systematic Reviews of Interventions. Version 5.1.0 [Updated March 2011]. The Cochrane Collaboration; 2011. Available from: www.cochranehandbook.org

47. Munn Z, Tufanaru C, Aromataris E. Data extraction and synthesis the steps following study selection in a systematic review. Am J Nurs. 2014;114(7):49-54. doi:10.1097/01.NAJ.0000451683.66447.89

48. Popay J, Roberts H, Sowden A, et al. Guidance on the Conduct of Narrative Synthesis in Systematic Reviews: A Product from the ESRC Methods Programme. 2006.

49. Ahmad NS, Ramil A, Islahudin F, Paraidathathu T. Medication adherence in patients with type 2 diabetes mellitus treated at primary health clinics in Malaysia. Patient Prefer Adherence. 2013;7:525-530. doi:10.2147/PPA.S44698

50. Al-Amer R, Ramjan L, Glew P, Randall S, Salamonson Y. Selfefficacy, depression, and self-care activities in adult jordanians with type 2 diabetes: the role of illness perception. Issues Ment Health Nurs. 2016;37(10):744-755. doi:10.1080/01612840.2016.1208692

51. Al-Sayah F, Soprovich A, Qiu W, Edwards AL, Johnson JA; Diabetic Foot Disease. Self-care and clinical monitoring in adults with type 2 diabetes: the Alberta's Caring for Diabetes (ABCD) cohort study. Can $J$ Diabetes. 2015;39:S120-S126. doi:10.1016/j. jcjd.2015.05.006

52. Asuzu CC, Walker RJ, Williams JS, Egede LE. Pathways for the relationship between diabetes distress, depression, fatalism and glycemic control in adults with type 2 diabetes. J Diabetes Complications. 2017;31:169-174. doi:10.1016/j.jdiacomp.2016.09.013

53. Chasens ER, Korytkowski M, Sereika SM, Burke LE. Effect of poor sleep quality and excessive daytime sleepiness on factors associated with diabetes self-management. Diabetes Educ. 2013;39(1):74-82. doi: $10.1177 / 0145721712467683$

54. Chen H-Y, Ruppert K, Charron-Prochownik D, Noullet WV, Zgibor JC. Effects of depression and antidepressant use on goal setting and barrier identification among patients with type 2 diabetes. Diabetes Educ. 2011;37(3):370-380. doi:10.1177/0145721711400662

55. Chen S-R, Chien Y-P, Kang C-M, Jeng C, Chang W-Y. Comparing self-efficacy and self-care behaviours between outpatients with comorbid schizophrenia and type 2 diabetes and outpatients with only type 2 diabetes. $J$ Psychiatr Ment Health Nurs. 2014;21:414-422. doi:10.1111/jpm.12101

56. Devarajoon C, Chinna K, Khamseh ME. Depression, distress and self-efficacy: the impact on diabetes self-care practices. PLoS One. 2017;12(3):e0175096. doi:10.1371/journal.pone. 0175096

57. Feil DG, Zhu CW, Sultzer DL. The relationship between cognitive impairment and diabetes self-management in a population-based community sample of older adults with type 2 diabetes. $J$ Behav Med. 2012;35:190-199. doi:10.1007/s10865-011-9344-6

58. Gonzalez JS, Safren SA, Cagliero E, et al. Depression, self-care, and medication adherence in type 2 diabetes: relationships across the full range of symptom severity. Diabetes Care. 2007;30:2222-2227. doi: $10.2337 / \mathrm{dc} 07-0158$

59. Hernandez R, Ruggiero L, Prohaska TR, et al. A cross-sectional study of depressive symptoms and diabetes self-care in African Americans and hispanics/latinos with diabetes: the role of self-efficacy. Diabetes Educ. 2016;42(4):452-461. doi:10.1177/ 0145721716654008 
60. Johnson ST, Al-Sayah F, Mathe N, Johnson JA. The relationship of diabetes-related distress and depressive symptoms with physical activity and dietary behaviors in adults with type 2 diabetes: a cross-sectional study. J Diabetes Complications. 2016;30:967-970. doi:10.1016/j.jdiacomp.2016.02.019

61. Lipscombe C, Smith KJ, Gariepy G, Schmitz N. Gender differences in the relationship between anxiety symptoms and physical inactivity in a community-based sample of adults with type 2 diabetes. Can J Diabetes. 2014;38:444-450. doi:10.1016/j.jcjd.2013.12.002

62. Malik S, Billimek J, Greenfield S, Sorkin DH, Ngo-Metzger Q, Kaplan SH. Patient complexity and risk factor control among multimorbid patients with type 2 diabetes: results from the R2D2C2 study. Med Care. 2013;51:180-185. doi:10.1097/ MLR.0b013e318273119b

63. Mut-Vitcu G, Timar B, Timar R, Oancea C, Citu IC. Depression influences the quality of diabetes-related self-management activities in elderly patients with type 2 diabetes: a cross-sectional study. Clin Interv Aging. 2016;11:471-479. doi:10.2147/CIA.S104083

64. Nau DP, Aikens JE, Pacholski AM. Effects of gender and depression on oral medication adherence in persons with type 2 diabetes mellitus. Gend Med. 2007;4(3):205-213.

65. O'Shea MP, Teeling M, Bennett K. Comorbidity, health-related quality of life and self-care in type 2 diabetes: a cross-sectional study in an outpatient population. Iran J Med Sci. 2015;184:623-630. doi:10.1007/s11845-014-1190-4

66. Schinckus L, Dangoisse F, Broucke S, Mikolajczak M. When knowing is not enough: emotional distress and depression reduce the positive effects of health literacy on diabetes self-management. Patient Educ Couns. 2018;101:324-330. doi:10.1016/j.pec.2017.08.006

67. Shin N, Hill-Briggs F, Langan S, Payne JL, Lyketsos C, Golden SH. The association of minor and major depression with health problem-solving and diabetes self-care activities in a clinic-based population of adults with type 2 diabetes mellitus. $J$ Diabetes Complications. 2017;31:880-885. doi:10.1016/j.jdiacomp.2017.01.026

68. Smith KJ, Pedneault M, Schmitz N. Investigation of anxiety and depression symptom co-morbidity in a community sample with type 2 diabetes: associations with indicators of self-care. Can J Public Health. 2015;106(8):e496-e501. doi:10.17269/CJPH.106.5170

69. Zuberi SI, Syed EU, Bhatti JA. Association of depression with treatment outcomes in type 2 diabetes mellitus: a cross-sectional study from Karachi, Pakistan. BMC Psychiatry. 2011;11(27). Available from: http://www.biomedcentral.com/1471-1244X/1411/1427

70. Aikens JE. Prospective associations between emotional distress and poor outcomes in type 2 diabetes. Diabetes Care. 2012;35:2472-2478. doi:10.2337/dc12-0181

71. Axon RN, Gebregziabher M, Hunt KJ, et al. Comorbid depression is differentially associated with longitudinal medication nonadherence by race/ethnicity in patients with type 2 diabetes. Medicine. 2016;95 (25):1-7. doi:10.1097/MD.0000000000003983

72. Gonzalez JS, Safren SA, Delahanty LM, et al. Symptoms of depression prospectively predict poorer self-care in patients with type 2 diabetes. Diabeteic Med. 2008;25:1102-1107. doi:10.1111/j.14645491.2008.02535.x
73. He X, Chen L, Wnag $\mathrm{K}$, Wu H, Wu J. Insulin adherence and persistence among chinese patients with type 2 diabetes: a retrospective database analysis. Patient Prefer Adherence. 2017;11:237-245. doi:10.2147/PPA.S123389

74. Kalsekar ID, Madhavan SS, Amonkar MM, et al. Depression in patients with type 2 diabetes: impact on adherence to oral hypoglycemic agents. Ann Pharcother. 2006;40:605-611. doi:10.1345/ aph.1G606

75. Kreyenbuhl J, Dixon LB, McCarthy JF, Suliman S, Ignacio RV, Valenstein M. Does adherence to medications for type 2 diabetes differ between individuals with vs without schizophrenia? Schizophr Bull. 2010;36(2):428-435. doi:10.1093/schbul/sbn106

76. O'Shea MP, Teeling M, Bennett K. An observational study examining the effect of comorbidity on the rates of persistence and adherence to newly initiated oral anti-hyperglycaemic agents. Pharmacoepidemiol Drug Saf. 2013;22:1336-1344. doi:10.1002/pds.3535

77. Palakodeti S, Uratsu CS, Schmittdiel JA, Grant RW. Changes in physical activity among adults with diabetes: a longitudinal cohort study of inactive patients with type 2 diabetes who become physically active. Diabeteic Med. 2015;32:1051-1057. doi:10.1111/dme.12748

78. Dixon JB, Browne JL, Mosely KG, et al. Severe obesity and diabetes self-care attitudes, behaviours and burden: implications for weight management from a matched case-controlled study. Results from diabetes MILES-Australia. Diabeteic Med. 2014;31:232-240. doi:10.1111/dme.12306

79. Wagner JA, Tennen H, Osborn CY. Lifetime depression and diabetes self-management in women with type 2 diabetes: a case-control study. Diabeteic Med. 2010;27:713-717. doi:10.1111/j.14645491.2010.02996.x

80. Kroese FM, Adriaanse MA, Ridder TDD. Are self-management interventions suitable for all? Comparing obese versus nonobese type 2 diabetes patients. Health Educ Behav. 2012;40(5):552-558. doi:10.1177/1090198112454285

81. Trief PM, Izquierdo R, Eimicke JP, et al. Adherence to diabetes self care for white, African-American and Hispanic American telemedicine participants: 5 year results from the IDEATel project. Ethn Dis. 2013;18(1):83-96. doi:10.1080/13557858.2012.700915

82. Bruce DG, Davis WA, Starkstein SE, Davis TME. Clinical risk factors for depressive syndrome in type 2 diabetes: the Fremantle Diabetes Study. Diabeteic Med. 2018;35:903-910. doi:10.1111/dme.13631

83. Alagiakrishnan K, Zhao N, Mereu L, Senior P, Senthilselvan A. Montreal cognitive assessment is superior to standardized mini-mental status exam in detecting mild cognitive impairment in the middle-aged and elderly patients with type 2 diabetes mellitus. Biomed Res Int. 2013;2013:1-5. Article ID 186106. doi:10.1155/2013/186106

84. Mendenhall E, Norris SA, Shidhaye R, Prabhakaran D. Depression and type 2 diabetes in low and middle income countries: a systematic review. Diabetes Res Clin Pract. 2014;103(2):276-285. doi:10.1016/ j.diabres.2014.01.001

85. Mendenhall E, Kohrt BA, Norris SA, Ndetel D, Prabhakaran D. Noncommunicable disease syndemics: poverty, depression, and diabetes among low-income populations. Lancet. 2017;389:951-963. doi:10.1016/S0140-6736(17)30402-6 


\section{Publish your work in this journal}

Diabetes, Metabolic Syndrome and Obesity: Targets and Therapy is an international, peer-reviewed open-access journal committed to the rapid publication of the latest laboratory and clinical findings in the fields of diabetes, metabolic syndrome and obesity research. Original research, review, case reports, hypothesis formation, expert opinion and commentaries are all considered for publication. The manuscript management system is completely online and includes a very quick and fair peer-review system, which is all easy to use. Visit http://www.dovepress.com/testimonials.php to read real quotes from published authors. 